\title{
In-stream net uptake regulates inorganic nitrogen export from catchments under base flow conditions
}

\author{
Susana Bernal, ${ }^{1}$ Daniel von Schiller, ${ }^{2}$ Eugènia Martí, ${ }^{1}$ and Francesc Sabater ${ }^{3}$ \\ Received 9 February 2012; revised 24 May 2012; accepted 26 May 2012; published 12 July 2012.
}

[1] We aimed to investigate the temporal variation of in-stream net dissolved inorganic nitrogen (DIN) areal uptake rates $\left(U_{D I N}\right.$, in $\left.\mu \mathrm{g} \mathrm{N} \mathrm{m}^{-2} \mathrm{~min}^{-1}\right)$ and its implications on regulating catchment $\mathrm{N}$ export, under base flow conditions. To do so, we estimated $U_{D I N}$ from longitudinal profiles of ambient DIN concentration (nitrate + ammonium) in two streams on a monthly basis during two hydrological years $(n=45)$. We found that in-stream DIN uptake and release did not offset each other $\left(U_{D I N} \neq 0\right)$ in half of the dates, and that $U_{D I N}>0$ occurred mostly in autumn. Based on these reach-scale uptake rates, we performed empirical calculations and model simulations to assess the potential of stream network DIN retention to regulate DIN export from catchments on an annual scale. The empirical approach consisted in up-scaling $U_{D I N}$ by means of a dynamic stream network analysis that considered temporal and spatial variation of $U_{D I N}$. The modeling approach consisted in applying different scenarios with the INCA model based on the natural range of empirical $U_{D I N}$ values. Our results showed that the contribution of stream network DIN retention to catchment DIN export increased when calculations accounted for the temporal variation of $U_{D I N}$. Both approaches suggested that stream network DIN retention can significantly reduce DIN export from headwater catchments under base flow conditions (from $4 \%$ to $38 \%$ ).

Citation: Bernal, S., D. von Schiller, E. Martí, and F. Sabater (2012), In-stream net uptake regulates inorganic nitrogen export from catchments under base flow conditions, J. Geophys. Res., 117, G00N05, doi:10.1029/2012JG001985.

\section{Introduction}

[2] Headwater streams are integrative recipients of nutrient export from terrestrial ecosystems as well as highly reactive ecosystems with a significant capacity to transform and retain nutrients, nitrogen in particular, during downstream transport [Bormann and Likens, 1967; Peterson et al., 2001; Mulholland et al., 2008]. However, the relevance of in-stream dissolved inorganic nitrogen (DIN) uptake at the catchment scale is still poorly understood, due to the constraints associated with up-scaling reach-scale empirical estimates to larger spatial scales, and the difficulty of incorporating temporal variation of in-stream DIN uptake as a result of changing environmental conditions [Boyer et al., 2006; Ensign and Doyle, 2006; Helton et al., 2011].

[3] Most empirical studies that have estimated in-stream DIN uptake are based on the nutrient spiraling concept and the use of in situ solute injections [Newbold, 1996]. These

\footnotetext{
${ }^{1}$ Biogeodynamics and Biodiversity Group, Center for Advanced Studies of Blanes (CEAB-CSIC), Blanes, Girona, Spain.

${ }^{2}$ Catalan Institute for Water Research, Scientific and Technological Park of the University of Girona, Girona, Spain.

${ }^{3}$ Department of Ecology, University of Barcelona, Barcelona, Spain.

Corresponding author: S. Bernal, Biogeodynamics and Biodiversity Group, Center for Advanced Studies of Blanes (CEAB-CSIC), Accés Cala St. Francesc 14, ES-17300 Blanes, Girona, Spain. (sbernal@ceab.csic.es)

Published in 2012 by the American Geophysical Union.
}

studies identified temperature and stream water DIN concentration among the key factors regulating in-stream DIN uptake [Ensign and Doyle, 2006; Mulholland and Webster, 2010]. Moreover, stream discharge can strongly control the capability of aquatic biota to cycle DIN because contact time between the water column and the streambed surface, where most of the organisms develop, depends on water residence time [Peterson et al., 2001]. Solute injection experiments, however, provide measurements of gross DIN uptake and do not account for $\mathrm{N}$ release, be that via inorganic or organic forms [Marti et al., 1997]. Therefore, such measurements could overestimate the stream capability to regulate catchment DIN export since part of the DIN assimilated by stream biota can be transported downstream after being mineralized [Hall et al., 2009a]. Thus, to estimate the potential contribution of in-stream DIN cycling to catchment DIN export, it is essential to use rates of net DIN uptake, that is the balance between DIN uptake (assimilation, denitrification, adsorption) and release (mineralization, desorption). However, in contrast to the large number of studies quantifying in-stream gross DIN uptake, those quantifying net DIN uptake are relatively scarce. Brookshire et al. [2009] have suggested that in-stream DIN uptake and release rapidly counterbalance each other, so that $\mathrm{N}$ cycling in streams tends toward steady state ( $\mathrm{N}$ uptake $\sim \mathrm{N}$ release) with minor influence on downstream $\mathrm{N}$ export. However, exceptions to this trend have been reported when environmental conditions favor denitrification [Mulholland et al., 2008], hydrological 
exchange with the hyporheic zone [Hall et al., 2009a], microbial immobilization or net growth of algal biomass [Roberts and Mulholland, 2007; Martí et al., 1997; Bernhardt et al., 2003]. Therefore, biogeochemical activity within the stream can lead to moments of disequilibrium when DIN release does not offset DIN uptake, which could potentially modify stream DIN export. How influential instream DIN uptake could be to catchment DIN export at the annual scale will depend on the frequency, the magnitude, and the duration of such disequilibrium episodes. To resolve this intriguing question, and due to the highly dynamic nature of stream ecosystems, it is crucial to account for the temporal variation of in-stream net DIN uptake.

[4] Model approaches can provide additional insights for understanding how DIN cycling in aquatic ecosystems influences DIN export at the catchment scale [Boyer et al., 2006; Helton et al., 2011]. Attempts have been made to include variation of in-stream uptake associated with changes in stream size to account for spatial variation along the stream network [Ensign and Doyle, 2006; Wollheim et al., 2006; Helton et al., 2011]. However, consideration of temporal variation of DIN uptake rates in these models is still an ongoing challenge; and thus, current integrated annual budgets referred to the whole stream network are subjected to several uncertainties [Wade et al., 2002, 2006; Boyer et al., 2006]. Few models describing catchment hydrology and DIN export deal with the temporal variation of in-stream $\mathrm{N}$ processes, among them, the widely used Integrated Catchment Model of Nitrogen (INCA) in which stream water temperature modulates daily variation of in-stream DIN processes [Wade et al., 2002].

[5] The aim of this study was to investigate the temporal variation of in-stream net DIN uptake, and to quantify its contribution to annual catchment DIN export. We measured in-stream net DIN areal uptake rates on a monthly basis and examined how they were influenced by key environmental variables (temperature, discharge, and stream DIN concentration). The study was restricted to base flow conditions, the most frequent hydrological condition over a water year, when in-stream net DIN uptake is expected to be maximized due to the high interaction between stream communities and nutrients in the water column [Peterson et al., 2001]. Further, by focusing on base flow conditions we minimized the potential confounding effects of changes in water and DIN sources during stormflow on the empirical calculation of instream net DIN areal uptake rates [von Schiller et al., 2011]. We applied two independent approaches to assess the contribution of in-stream net DIN uptake to catchment DIN export. First, we upscaled in-stream net DIN areal uptake rates to the whole stream network and integrated them at annual scale (empirical approach). Second, we used the observed natural range of these reach-scale rates to apply different scenarios (with and without in-stream DIN cycling) with the INCA model (modeling approach). The study was conducted in two forested headwater catchments (one subhumid and one semiarid) that together covered a wide range of climatic, hydrological and stream water DIN concentrations. We show that these two headwater streams can alternatively reach biogeochemically steady state (DIN uptake DIN release) or undergo periods of disequilibrium between DIN uptake and release. Our results suggest that these disequilibrium periods could reduce annual catchment DIN export under base flow conditions by $4 \%-38 \%$.

\section{Site Description}

[6] The Santa Fe stream (second order) and Fuirosos stream (third order) drain forested headwater catchments dominated by siliceous geology located in Catalonia (NE Spain; Figure 1). The Santa Fe catchment $\left(2.6 \mathrm{~km}^{2}, 1419 \mathrm{~m}\right.$ a.s.l.) has a Mediterranean subhumid climate, while the Fuirosos catchment $\left(14.4 \mathrm{~km}^{2}, 361 \mathrm{~m}\right.$ a.s.1.) has a Mediterranean semiarid climate [Ninyerola et al., 2000]. The mean annual precipitation is higher and the range of mean monthly air temperature is lower in Santa Fe than in Fuirosos (Table 1). Consequently, annual potential evapotranspiration is higher in Fuirosos than in Santa Fe, which results in lower annual stream discharge and runoff coefficient in the former than in the latter (Table 1).

[7] Mixed forests of coniferous (Abies alba) and deciduous (Fagus sylvatica) species cover the Santa Fe catchment, while the Fuirosos catchment is dominated by evergreen perennial forests (Quercus suber, Pinus halepensis) at the lower elevations and deciduous forests (Castanea sativa, Corylus avellana, Quercus pubescens) at the higher elevations. In Santa Fe, riparian vegetation ( $F$. sylvatica, Sambucus nigra) is poorly developed compared to that in Fuirosos (Alnus glutinosa, Platanus hispanica). The two catchments are located in natural protected areas with low anthropogenic impact. Because of local climate, Santa $\mathrm{Fe}$ has permanent flow year-round, while Fuirosos has intermittent flow with summer no-flow periods of variable duration among years [Bernal et al., 2005]. In the two streams, DIN is dominated by nitrate $\left(\mathrm{NO}_{3}^{-}\right)$, but the concentration is higher, expands a wider range of values and shows a different seasonal pattern in Fuirosos than in Santa Fe [von Schiller et al., 2008] (Figure 2). In the two streams, the concentration of ammonium $\left(\mathrm{NH}_{4}^{+}\right.$; mean $\left.<20 \mu \mathrm{g} \mathrm{N} \mathrm{L}^{-1}\right)$ and nitrite $\left(\mathrm{NO}_{2}^{-}\right.$; mean $\left.<2 \mu \mathrm{g} \mathrm{N} \mathrm{L}^{-1}\right)$ are low and show no clear seasonal pattern [von Schiller et al., 2008].

\section{Methods}

\subsection{Field Sampling and Laboratory Analysis}

[8] We selected one representative stream reach at Santa Fe $(140 \mathrm{~m})$ and Fuirosos $(80 \mathrm{~m})$ located at the mouth of each catchment. From September 2004 until August 2006, we collected water samples and measured conductivity (at $20^{\circ} \mathrm{C}$ ) on a monthly basis at eight locations along each of the two selected stream reaches. We estimated discharge $(Q$, in $\mathrm{L} \mathrm{s}^{-1}$ ) by conducting short-term constant rate additions of a hydrological tracer (i.e., $\mathrm{NaCl}$ ) and recording conductivity at the bottom of the reach [Gordon et al., 2004]. We measured average effective water column depth (from a $20-\mathrm{cm}$ interval transect), wetted width, and water temperature $\left(T\right.$, in $\left.{ }^{\circ} \mathrm{C}\right)$ at each sampling location and averaged values from all sampling locations to provide a value for the entire reach. We repeated this sampling procedure on 25 and 20 different sampling dates in Santa Fe (hereafter, subhumid stream) and Fuirosos (hereafter, semiarid stream) respectively. We additionally collected water samples and measured $Q$ using the velocity-area method [Gordon et al., 2004] in a single cross-section located at the bottom of 


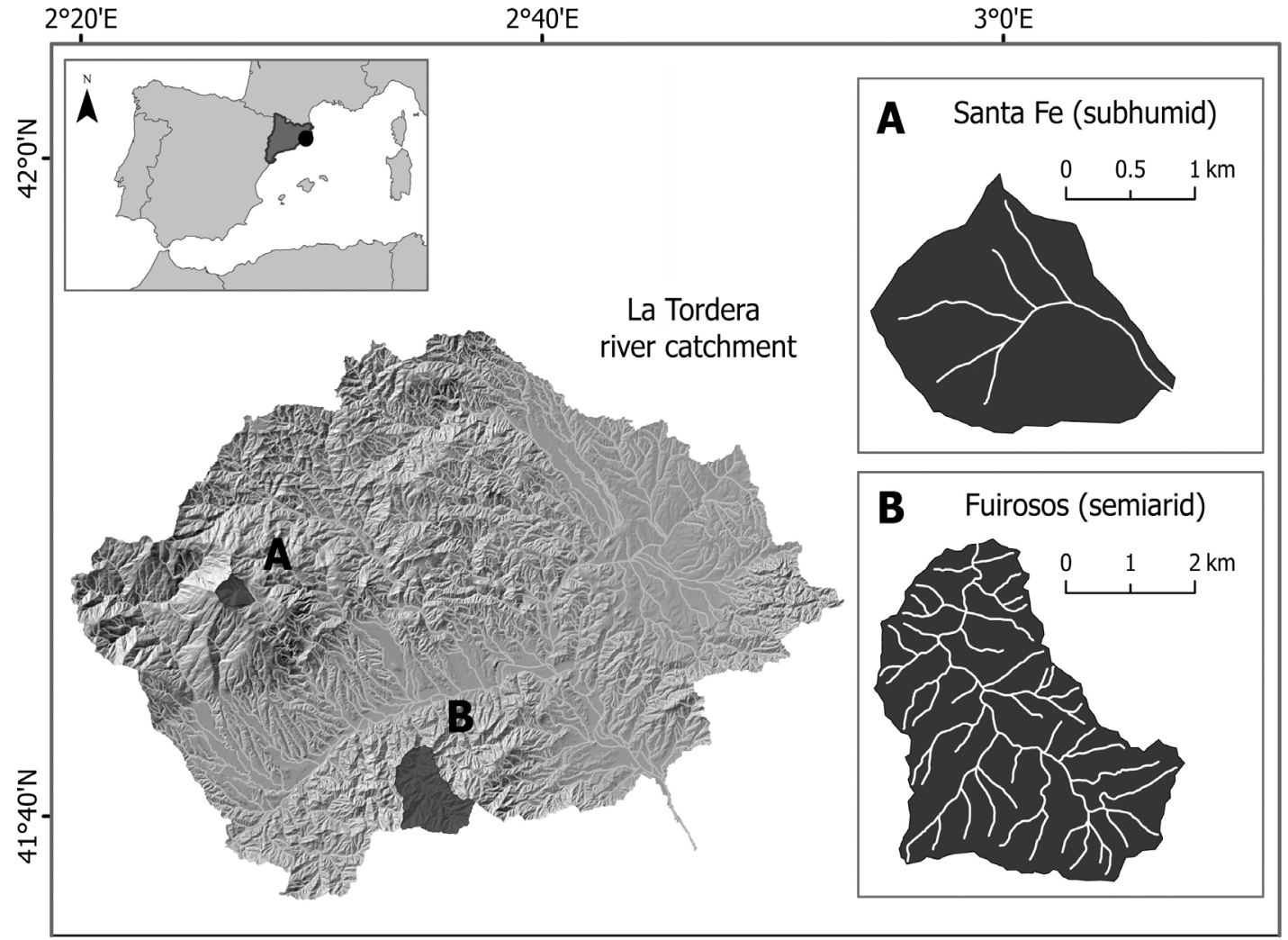

Figure 1. Geographical location and drainage network of the (a) Santa Fe (subhumid), and (b) Fuirosos (semiarid) catchments within the watershed of the river La Tordera (Catalonia, NE Spain).

each reach on a biweekly basis. To correct small discrepancies between the constant rate addition and velocityarea methods, we applied a correction factor to $Q$ values estimated with the latter. This correction factor was based on the comparison of pairs of $Q$ values resulting from applying simultaneously the two methods. We analyzed stream water samples colorimetrically for the concentration of $\mathrm{NO}_{2}^{-}$and $\mathrm{NO}_{3}^{-}$(EN ISO 13395) on a Bran+Luebbe TRAACS 2000 Autoanalyzer (Nordersted, Germany), and for $\mathrm{NH}_{4}^{+}\left(\mathrm{EN}\right.$ ISO 11732) on a Skalar $\mathrm{San}^{+}$Autoanalyzer (Breda, Netherlands).

\subsection{In-Stream Net DIN Areal Uptake Rates}

[9] We calculated in-stream net DIN areal uptake rates ( $U_{D I N}$, in $\mu \mathrm{g} \mathrm{N} \mathrm{m}^{-2} \mathrm{~min}^{-1}$ ) for each sampling date using the longitudinal variation in DIN concentration along the stream reach. For all sampling dates, we observed a small contribution of groundwater inputs to stream discharge (low dilution) and a small difference in DIN concentrations between hyporheic groundwater and stream water in the two study reaches. These requirements were essential to calculate successfully $U_{D I N}$ from the longitudinal variation of DIN concentration. Additional details, assumptions, and limitations of this empirical method can be found in von Schiller et al. [2011]. Briefly, we estimated a net uptake coefficient per unit of reach length $\left(k\right.$, in $\left.\mathrm{m}^{-1}\right)$ using the following first-order equation:

$$
N_{x}=N_{\text {top }}\left(\operatorname{Cond}_{x} / \operatorname{Cond}_{\text {top }}\right) e^{-k x},
$$

where $N$ is stream water DIN concentration (in $\mu \mathrm{g} \mathrm{N} \mathrm{L}^{-1}$ ) and Cond is stream water conductivity (in $\mu \mathrm{S} \mathrm{cm}^{-1}$ ) at the top of the reach (top) and at each location from the top of the reach $(x$, in $\mathrm{m})$. We calculated $k$ and its $\pm 95 \%$ confidence interval from the regression between Cond-corrected stream water $\mathrm{N}$ concentration (i.e., $\ln N_{x}$ ) and the downstream distance $(x)$ after linearizing equation (1). Then, we calculated $U_{D I N}$ as follows:

$$
U_{D I N}=\left(Q N_{A v g} k\right) / w,
$$

where $N_{A v g}$ is the average stream water DIN concentration from the eight locations along the reach and $w$ is the average wetted width (in m). $U_{D I N}$ integrates uptake and release

Table 1. Environmental Variables for the Subhumid and Semiarid

\begin{tabular}{|c|c|c|c|c|c|c|}
\hline \multirow[b]{2}{*}{ Water Year } & \multirow[b]{2}{*}{ Site } & $\mathrm{T}$ & $\mathrm{P}$ & PET & Q & $\mathrm{RC}$ \\
\hline & & ${ }^{\circ} \mathrm{C}$ & \multicolumn{3}{|c|}{$\mathrm{mm}$} & $\%$ \\
\hline \multirow[t]{2}{*}{ 2004-2005 } & Sul & $31-$ & 825 & 1020 & 94 & 11 \\
\hline & Sem & $13.4(2.5$ & 36 & 1418 & 25 & 7.0 \\
\hline \multirow[t]{2}{*}{ 2005-2006 } & Subhumid & $9.1(3.8-15.9)$ & 1159 & 958 & 229 & 19 \\
\hline & Semiarid & $12.5(3.0-21.4)$ & 580 & 1368 & 77 & 13 \\
\hline
\end{tabular}
Catchments During Two Consecutive Water Years ${ }^{\mathrm{a}}$

${ }^{a}$ Annual average and range (min-max) of air temperature $(T)$, annual precipitation $(P)$, potential evapotranspiration $(P E T)$, stream discharge $(Q)$, and runoff coefficient $(R C=Q / P)$. We computed $P E T$ with the Penman equation [Campbell and Norman, 1998] from climatic data provided by the Montnegre-Corredor and the Montseny Natural Protected Areas from meteorological stations located nearby our study sites (Can Lleonart and Dos Rius) 


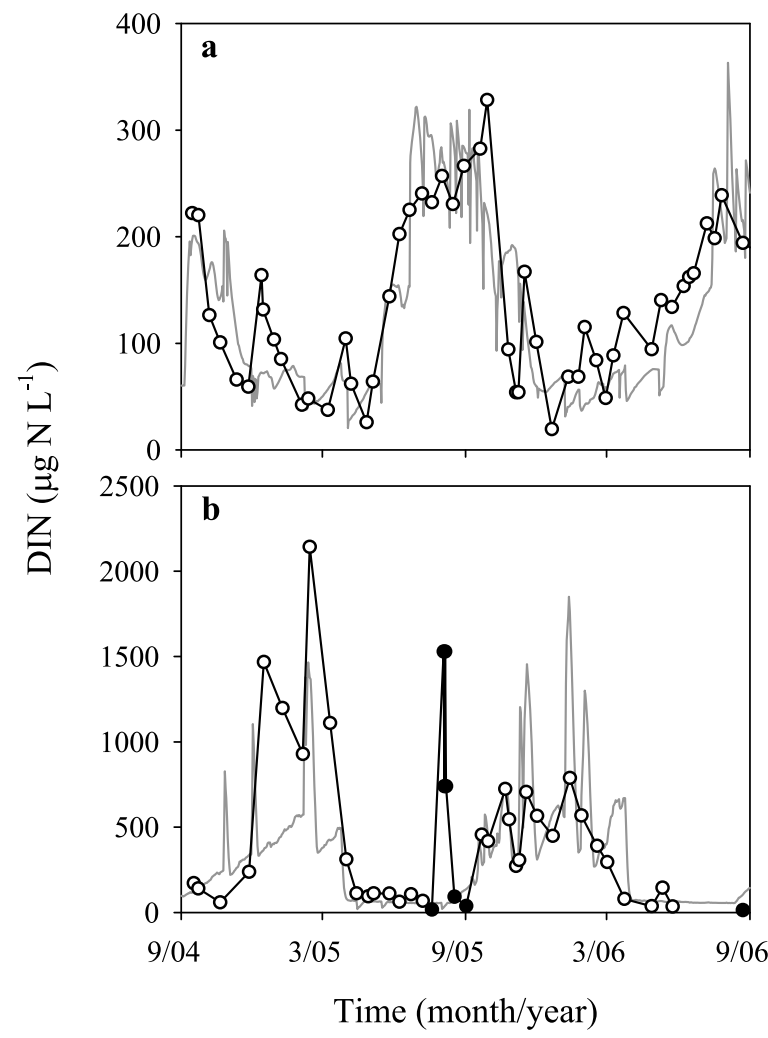

Figure 2. Stream water DIN concentration (black line with open circles) for the (a) subhumid and (b) semiarid catchments during the study period. Gray lines show DIN concentration simulated with the INCA model for the case $K_{c}=0$ (no in-stream net DIN uptake). The goodness of fit $\left(\mathrm{r}^{2}\right)$ between measured and simulated values was 0.61 and 0.46 for the subhumid and the semiarid catchment, respectively (in both cases $\mathrm{p}<0.01$ ). Black circles in (b) correspond to DIN concentration for ephemeral and flashy storms during the summer dry period that were not included in the correlation analysis.

processes occurring along the reach, and can be positive (DIN uptake $>$ DIN release), negative (DIN uptake $<$ DIN release) or nil (DIN uptake $\sim$ DIN release) depending on the value of $k$. For each date, we estimated an upper and lower limit of $U_{D I N}$ based on the previously calculated $\pm 95 \%$ confidence interval of $k$. We assumed that $U_{D I N}$ was undistinguishable from 0 (DIN uptake $\sim$ DIN release) when the interval contained zero [von Schiller et al., 2011].

\subsection{Catchment Export and Stream Network Retention of DIN}

[10] Based on our reach-scale uptake rates, we performed empirical calculations and model simulations to assess the potential of stream network DIN retention to regulate DIN export from catchments on an annual scale. First, we upscaled our reach-scale empirical estimates of $U_{D I N}$ to the whole stream network by means of a dynamic stream network analysis (empirical approach). Second, we applied different scenarios (with and without in-stream DIN cycling) using the INCA model based on the natural range of values of $U_{D I N}$ (modeling approach).

\subsubsection{Empirical Approach}

[11] For each water year, we calculated DIN export per unit of catchment area under base flow conditions (CatExp, in $\mathrm{kg} \mathrm{N} \mathrm{ha}^{-1}$ year $^{-1}$ ) by linearly interpolating the product between instantaneous stream water DIN concentration and $Q$ from each sampling date. We considered that the water year started on the 1 September for the subhumid stream and on the first day after flow recovery for the semiarid stream. To estimate annual stream network retention of DIN under base flow conditions we linearly interpolated the product between $U_{D I N}$ values and stream channel area $(A)$ between consecutive sampling dates by assuming that both variables changed with stream order [Wollheim et al., 2006; Ensign and Doyle, 2006; Gordon et al., 2004]. When $U_{D I N}$ was not available for a particular stream order $d$, we estimated $U_{D I N, j, d}$ for each sampling date $j$ ( $j$ as for journey) by using the ratio between median values of $U_{D I N}$ for different stream orders based on a quantitative synthesis of 404 individual experiments reported by Ensign and Doyle [2006, Table 2]. Specifically, we considered the ratio $U_{D I N, j, 1}: U_{D I N, j, 2}=$ 0.897 for the subhumid catchment, and the ratios $U_{D I N, j, 1}$ : $U_{D I N, j, 3}=0.736$ and $U_{D I N, j, 2}: U_{D I N, j, 3}=0.821$ for the semiarid catchment. We assumed that the whole stream network upstream of the sampling point was biogeochemically 'active' (all stream orders included), and we calculated the 'active' stream channel area $\left(A_{j, d}\right.$ in $\left.\mathrm{km}^{2}\right)$ as:

$$
A_{j, d}=L_{d} w_{j, d} .
$$

$L_{d}$ (in $\mathrm{km}$ ) was the total length of the stream network for a given stream order $d$. To measure $L_{d}$, we summed up all stream segments for each stream order obtained from a river network LandSat map 1:50000 (BT-50M v.3.0) provided by the Catalan Water Agency (www.aca-web.gencat.cat). The total stream length $L$ was 5.3 and $45.3 \mathrm{~km}$ in Santa Fe and Fuirosos, respectively. To account for variation in stream channel area with changing stream order, we considered that $w_{j}$ changed proportionally with drainage area. We calculated the width-to-drainage-area ratio on each sampling date at the study reaches $\left(r_{j}\right.$, in $\left.\mathrm{km}^{-1}\right)$, and we used $r_{j}$ as a proxy to estimate the average $w_{j, d}$ for the stream network upstream of the sampling point [Gordon et al., 2004]. Average $A_{j}$ over time was $<0.2 \%$ of the total catchment area in the two cases (Santa Fe: $0.53 \pm 0.05$ ha (average \pm standard deviation); Fuirosos: $2.3 \pm 0.25 \mathrm{ha}$ ).

[12] For each water year, we calculated the annual stream network DIN retention under base flow conditions per unit of catchment area (StrRet, in $\mathrm{kg} \mathrm{N} \mathrm{ha}^{-1}$ year $^{-1}$ ) with and without temporal variation of $U_{D I N}$. In the former case, we linearly interpolated the product between $U_{D I N, j, d}$ and $A_{j, d}$ between sampling dates and summed up the obtained values for each water year. In the later case, we considered that $U_{D I N}$ was constant over time and equal to the average of $U_{D I N, j}$ values. We calculated the relative contribution of StrRet to CatExp as $100 \times[$ StrRet $/(\operatorname{CatExp}+$ StrRet $)]$ assuming that the empirical estimate of CatExp already included the net result of in-stream DIN uptake and release. We acknowledge that our approach may be an oversimplification of the actual DIN retention in these two stream networks because $U_{D I N}$ may vary at other spatiotemporal scales not captured by this study, yet we think that this is a 
useful exercise to illustrate the potential role of in-stream net DIN uptake on regulating catchment DIN export.

\subsubsection{Modeling Approach}

[13] The semi-distributed INCA model (v1.11.10) is a process-based model that integrates catchment hydrology and DIN cycling in plant and soil to simulate daily stream DIN concentration and flux (Text S1 in the auxiliary materials). ${ }^{1}$ We chose this model because it is one of the few models available that includes DIN cycling in the stream compartment and accounts for its temporal variation [Wade et al., 2002]. Another benefit of using INCA is that the temporal resolution of model simulations is higher than that of our empirical database for which we had to assume a linear behavior between monthly samples. We used the model output to obtain an independent estimate of the stream network DIN retention that could be compared to that obtained with the empirical approach. The structure of the INCA model allowed us to simulate annual catchment DIN export with and without in-stream DIN cycling and then, to estimate annual stream network DIN retention $\left(\right.$ StrRet $\left._{\text {sim }}\right)$ by difference.

[14] The INCA in-stream compartment considers denitrification and nitrification, and operates as a multireach system where soil water and groundwater drain into the stream reaches. Changes in $\mathrm{N}$ concentration within the stream are modeled as first-order reaction processes and in-stream processing rates are dependent on water temperature as follows:

$$
K_{c}^{T}=K_{c} 1.047^{(T-20)},
$$

where $K_{c}$ (in days ${ }^{-1}$ ) is the uptake coefficient per unit of time. We used our empirical estimates of $U_{D I N}$ to calculate $K_{c}$ as:

$$
K_{c}=\left(U_{D I N} / h N_{\text {Avg }}\right) \times 1440,
$$

where $h$ is the average effective water column depth (in m) and 1440 is a time unit factor to convert minutes to days. The model considers denitrification as the only mechanism capable of regulating stream DIN concentration, overlooking other in-stream processes that can either retain or release DIN in natural systems (assimilation, adsorption, mineralization, desorption), and thus contribute to change in-stream water DIN concentration. Hence, for our purposes, it was reasonable to assume that the so-called 'denitrification' rate in the INCA model actually reflected the in-stream net DIN uptake, or in other words, the net result of all those biogeochemical processes that remove, store and/or release DIN within the stream.

[15] To estimate StrRet $_{\text {sim }}$, we first considered the null model with no in-stream $\mathrm{N}$ uptake $\left(K_{c}=0\right)$. We adjusted the hydrological, plant, and soil model parameters to get the best fit between simulated and observed stream water DIN concentrations for both, the subhumid and semiarid catchments. To fit these parameters, we used empirical data when available; otherwise, we used published values for systems similar to ours and we adjusted them manually to obtain the best match between simulated and measured data (Text S1 in

\footnotetext{
${ }^{1}$ Auxiliary materials are available in the HTML. doi:10.1029/ 2012JG001985.
}

the auxiliary materials). Then we applied the model using the average $K_{c}\left(K_{c A v g}\right)$ estimated for each site. To estimate the contribution of StrRet sim to simulated catchment export $\left(C_{a t} \operatorname{Exp}_{\text {sim }}\right)$, we calculated the difference in CatExp sim between the null model and the in-stream scenarios. We calculated the relative contribution of StrRet sim ${ }_{\text {sim }}$ to CatEp $\operatorname{Ex}_{\text {sim }}$ as $100 \times\left[\right.$ StrRet $\left._{\text {sim }} / \operatorname{CatExp}_{\operatorname{sim}, \mathrm{k}=0}\right]$ for each catchment and for each water year.

\subsection{Statistical Analysis}

[16] We grouped empirical data by season (calendar dates) and applied a Wilcoxon/Kruskal Wallis test to examine differences in $U_{D I N}$ between streams. We applied a MannWhitney test to investigate whether $U_{D I N}$ was significantly different among seasons. For the semiarid catchment, the summer season coincided with the period with no streamflow rather than with the calendar dates. We determined the statistical significance of the correlation between $U_{D I N}$ and environmental variables (Q, T, DIN concentration) with a Spearman rho coefficient $(\rho)$. We used non-parametric tests because data sets were relatively small, not normally distributed, and showed heterocedasticity [Zar, 2010]. We used the standard deviation (SD) and the coefficient of variation (CV) as measures of dispersion of the data. The $\mathrm{CV}$ is unitless, thus it allows comparing the relative dispersion between data sets regardless of the actual magnitude or units of measurement of the data [Zar, 2010]. For each season, we calculated the proportion of $U_{D I N}>0, U_{D I N}<0$, and $U_{D I N}=$ 0 , and then we tested whether the proportions for a given season were statistically different from the others by using a contingency-table analysis [Zar, 2010]. When differences were statistically significant, we applied a Tukey-test to determine which specific proportions were different from which others [Zar, 2010]. In all cases, differences were considered significant if $\mathrm{p}<0.05$.

\section{Results}

\subsection{Temporal Variation of In-Stream Net DIN Areal Uptake Rates}

[17] Average $U_{D I N}$ was slightly positive in both streams $\left(9.6 \pm 107.4\right.$ (average $\pm \mathrm{SD}$ ) and $6 \pm 18 \mu \mathrm{g} \mathrm{N} \mathrm{m}{ }^{-2} \mathrm{~min}^{-1}$ for the semiarid and subhumid streams, respectively). $U_{D I N}$ was not statistically different between streams (Wilcoxon/ Kruskal Wallis test, $S=449, \mathrm{p}=0.81$ ), but exhibited higher variation in the semiarid stream $(\mathrm{CV}=1125 \%)$ than in the subhumid stream $(\mathrm{CV}=257 \%)$ (Figure 3$)$.

[18] In-stream DIN uptake and release processes counterbalanced each other $\left(U_{D I N} \sim 0\right)$ as often as they did not $\left(U_{D I N} \neq 0\right)$. When data from the two streams were pooled together, $U_{D I N} \sim 0$ in $52 \%, U_{D I N}>0$ in $35 \%$, and $U_{D I N}<0$ in $13 \%$ of the dates. There were no significant differences in $U_{D I N}$ among seasons (Mann-Whitney test, $\mathrm{p}>0.05$; Figure 4a). However, the proportion of dates with $U_{D I N}>0$ in autumn $(>60 \%)$ was significantly higher than in any other season (Tukey-test, $\mathrm{q}=3.572, \mathrm{p}<0.05$ ) (Figure $4 \mathrm{~b}$ ). From autumn to summer, the proportion of dates with $U_{D I N}>0$ decreased while that of dates with $U_{D I N} \sim 0$ increased (Figure $4 b$ ).

[19] The two streams showed a strong and contrasting correlation between DIN concentration and $T$ (Spearman $\rho=$ $+0.75, \mathrm{n}=25$ for the subhumid stream; Spearman $\rho=$ 


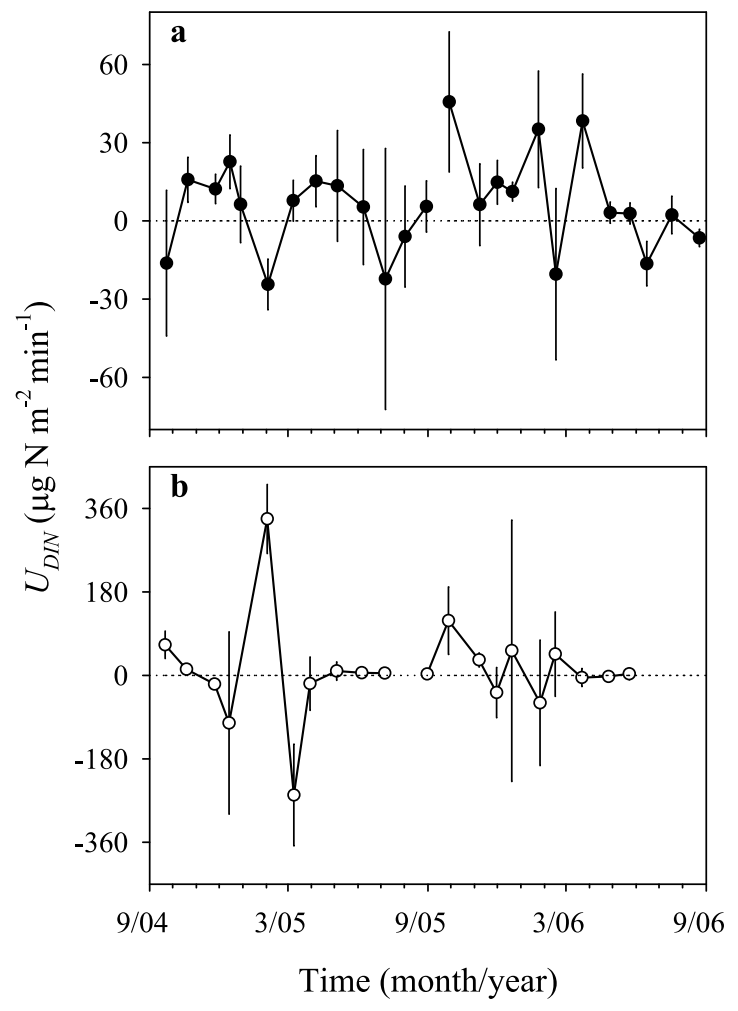

Figure 3. In-stream net DIN areal uptake rates $\left(U_{D I N}\right)$ for the (a) subhumid and (b) semiarid catchments measured monthly during the study period. Error bars are the $\pm 95 \%$ confidence interval. The dotted line indicates $U_{D I N}=0$ (DIN uptake $\sim$ DIN release).

$-0.78, \mathrm{n}=20$ for the semiarid stream; $\mathrm{p}<0.001$ for both streams). Nevertheless, there was no relationship between $U_{D I N}$ and $T$ ( $\mathrm{p}>0.05$ for both streams). Moreover, $U_{D I N}$ was not correlated with $Q$ or with stream water DIN ( $\mathrm{p}>0.05$ for both streams). We further examined the correlation between $U_{D I N}$ and environmental variables by considering only cases for which $U_{D I N} \neq 0$ for the two streams together. Cases with $U_{D I N}<0$ (net DIN release) were strongly correlated with $T$ (Spearman $\rho=+0.88, \mathrm{p}=0.018, \mathrm{n}=6$ ). In contrast, the cases with $U_{D I N}>0$ (net DIN uptake) did not correlate with $T$, but with stream water DIN concentration (Spearman $\rho=+0.83$, $\mathrm{p}<0.001, \mathrm{n}=16)$.

\subsection{Contribution of Stream Network DIN Retention to Catchment DIN Export}

\subsubsection{Results From Empirical Data}

[20] The annual StrRet ranged from 0.02 to $0.14 \mathrm{~kg} \mathrm{~N}$ ha $^{-1}$ year $^{-1}$ at the two studied catchments, being 14\%-38\% the relative contribution of StrRet to CatExp (Table 2). For a given water year, the CatExp varied $<35 \%$ between the two catchments (Table 2). Contrastingly, the difference in CatExp between the two water years was 311\% and 149\% for the semiarid and subhumid catchments, respectively (Table 2). The relative contribution of StrRet to CatExp was higher when the temporal variation of $U_{D I N}$ was included in the StrRet estimates, except for the driest year in the subhumid catchment (Table 2).

\subsubsection{Results From Simulated Data}

[21] The null model $\left(K_{c}=0\right)$ successfully recreated the magnitude and the seasonality of DIN concentration, explaining $61 \%$ and $46 \%$ of the total measured variation at the subhumid and semiarid streams, respectively (Figure 2). The simulated temporal variation of $K_{c}\left(K_{c}^{T}\right)$ was an order of magnitude lower $(\mathrm{CV}<35 \%)$ than the temporal variation observed with the empirical $K_{c}$ values $(\mathrm{CV}$, range: $228.8 \%$, -8.3 to 14.2 days $^{-1}$ for the subhumid; $286.7 \%,-5.7$ to 9.3 days $^{-1}$ for the semiarid). The relative contribution of StrRet $_{\text {sim }}$ to CatExp sim $_{\text {sas }} 10$ times lower for the subhumid catchment than for the semiarid catchment (Table 2). The relative contribution of stream network DIN retention to catchment DIN export was similar between the empirical and modeling approaches for the semiarid catchment, whereas for the subhumid catchment the modeling approach simulated a contribution of stream network DIN retention to catchment DIN export substantially lower than estimated with the empirical approach (Table 2).

\section{Discussion}

\subsection{Temporal Variation of In-Stream Net DIN Uptake}

[22] Stream ecosystems may regulate DIN export from catchments if the magnitude and frequency of biogeochemical
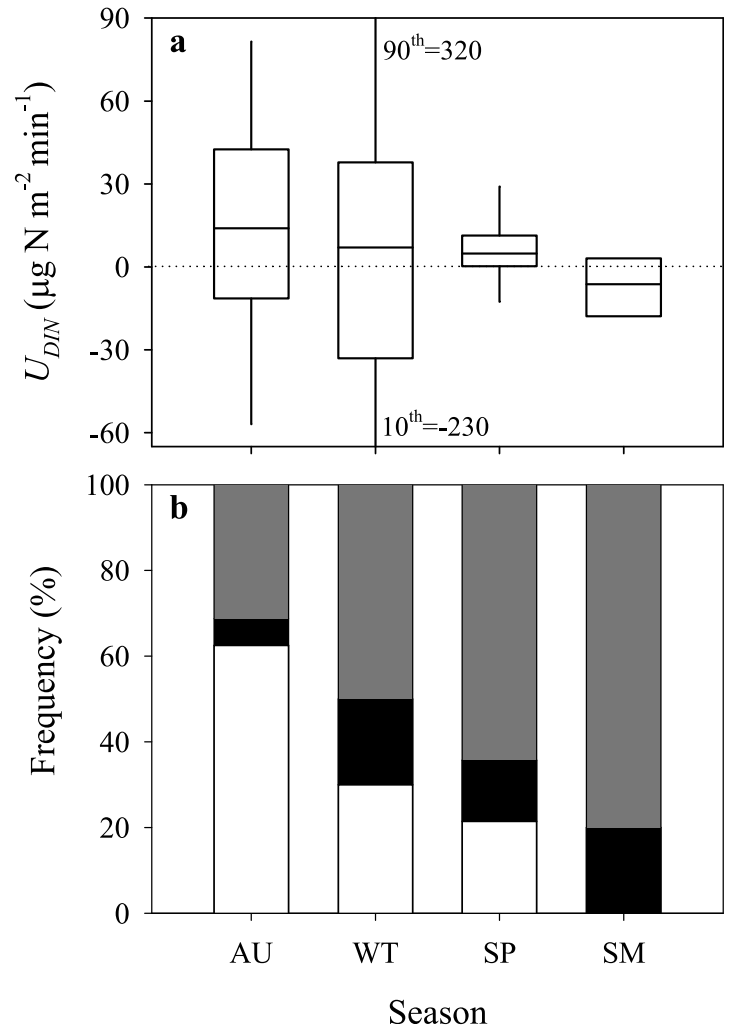

Figure 4. (a) Box plot with values of in-stream net DIN areal uptake rate $\left(U_{D I N}\right)$ for the two catchments grouped together by season. The line is the median; the limits of the box are the 25 th and the 75 th percentiles; whiskers are the 10th and the 90th percentiles. (b) Proportion of dates with $U_{D I N}>0$ (white bars), $U_{D I N}<0$ (black bars), and $U_{D I N} \sim$ 0 (gray bars) for the two catchments grouped together by season. 
Table 2. Empirical and Model Estimates of Catchment DIN Export and Stream Network DIN Retention for the Subhumid and Semiarid Catchments for Two Consecutive Water Years ${ }^{\mathrm{a}}$

\begin{tabular}{|c|c|c|c|c|c|c|c|}
\hline \multirow[b]{4}{*}{ Water Year } & \multirow[b]{4}{*}{ Site } & \multicolumn{3}{|c|}{ Empirical Approach } & \multicolumn{3}{|c|}{ Modeling Approach } \\
\hline & & \multicolumn{3}{|c|}{ StrRet } & \multicolumn{3}{|c|}{ CatExp $_{\text {sim }}$} \\
\hline & & CatExp & $U$ Variable & $U$ Constant & $K_{c}=0$ & $K_{c}=K_{c A v g}$ & StrRet $_{\text {sim }}$ \\
\hline & & \multicolumn{3}{|c|}{$\mathrm{kg} \mathrm{N} \mathrm{ha}^{-1}$} & \multicolumn{3}{|c|}{$\mathrm{kg} \mathrm{N} \mathrm{ha}^{-1}$} \\
\hline \multirow[t]{2}{*}{ 2004-2005 } & Subhumid & 0.095 & $0.026(21.3 \%)$ & $0.058(37.8 \%)$ & 0.099 & 0.095 & $0.004(4.0 \%)$ \\
\hline & Semiarid & 0.126 & $0.2(61.3 \%)$ & $0.065(34.0 \%)$ & 0.112 & 0.072 & $0.04(35.7 \%)$ \\
\hline \multirow{2}{*}{$2005-2006$} & Subhumid & 0.394 & $0.131(24.9 \%)$ & $0.063(13.8 \%)$ & 0.335 & 0.323 & $0.012(3.6 \%)$ \\
\hline & Semiarid & 0.314 & $0.123(28.2 \%)$ & $0.065(17.1 \%)$ & 0.435 & 0.285 & $0.15(34.5 \%)$ \\
\hline
\end{tabular}

\footnotetext{
${ }^{a}$ Annual catchment export of DIN (CatExp), annual stream network DIN retention (StrRet) calculated using a stream network analysis conceived for upscaling reach-scale estimates of $U_{D I N}$ (empirical approach). Empirical calculations were done with ( $U$ variable) and without ( $U$ constant) temporal variation of $U_{D I N}$. The same variables were estimated using the INCA model $\left(\right.$ CatExp $_{\text {sim }}$, StrRet $\left.t_{\text {sim }}\right)$. The StrRet sim was calculated by subtracting $\operatorname{CatExp}_{\operatorname{sim}}$ obtained with the $K_{c}=0$ scenario (no in-stream DIN cycling) to $\operatorname{CatExp}_{\operatorname{sim}}$ obtained with the $K_{c}=K_{c A v g}$ scenario (with in-stream DIN cycling). For both approaches, the relative contribution of stream retention to catchment DIN export is indicated in parenthesis.
}

disequilibrium $\left(U_{D I N} \neq 0\right)$ is high. Some studies have reported positive in-stream net uptake rates during some periods [Grimm et al., 1981; Roberts and Mulholland, 2007], while others have shown no evidence for in-stream net uptake and claim that streams are generally at biogeochemical steady state [Brookshire et al., 2009]. Our extensive data set indicates that both situations can alternate over time under base flow conditions in a given stream, highlighting the dynamic nature of stream ecosystems. We found that DIN uptake and release did not offset each other on half of the dates, and both studied streams had slightly mean positive values of $U_{D I N}$ indicating that, at least under base flow conditions, streams were acting as net sinks of DIN during a considerable proportion of time. In addition, $13 \%$ of the dates showed $U_{D I N}<0$, evidence that stream ecosystems can also contribute to increase DIN export from catchments during base flow periods, possibly through mineralization of organic $\mathrm{N}$ forms. These results suggest that periods of in-stream biogeochemical disequilibrium may be frequent, at least for DIN under base flow conditions.

[23] Although none of the environmental factors considered in this study was a good predictor of $U_{D I N}$, we found that values of $U_{D I N}>0$ occurred more often in autumn than in any other season. In both streams, large stocks of organic matter accumulated in the channel during late summer and early autumn, which increase hydrological retention and lead to high values of ecosystem respiration [Acuña et al., 2004; Argerich et al., 2008]. These conditions may favor in-stream net DIN uptake in autumn as shown by Roberts and Mulholland [2007] in a temperate headwater stream. Our results support these previous findings and suggest that periods of high organic matter availability enhance positive net DIN uptake rates especially in streams with a welldeveloped canopy cover and dominance of heterotrophic metabolism.

[24] The lack of correlation between $U_{D I N}$ and the environmental variables found in this study contrasts with previous studies that identified discharge, stream DIN concentration and, to a minor extent, temperature as key factors controlling in-stream gross DIN uptake [Butturini and Sabater, 1998; Peterson et al., 2001; Hall et al., 2009b]. These studies argued that high stream discharge decreases the efficiency to take up nutrients by reducing the contact area and time between stream water column and biogeochemically reactive zones [Butturini and Sabater, 1998; Peterson et al., 2001]. Moreover, high DIN concentration contributes to reduce the efficiency of stream biota to assimilate DIN due to a saturation effect [O'Brien et al., 2007; Hall et al., 2009b]. Results previously reported for gross DIN uptake in the same streams studied here agreed with these findings [von Schiller et al., 2008]. However, in the present study we did not find any clear influence of stream discharge, DIN concentration or temperature on the variation of $U_{D I N}$. In addition, we did not find significant differences in $U_{D I N}$ between the two streams, despite that average DIN concentration was threefold higher in the semiarid stream than in the subhumid stream. Our results are puzzling because although $U_{D I N}$ was extremely variable over time none of the physical and chemical variables considered here were able to explain a significant part of its variance. This result complicates the possibility to predict the temporal variation of $U_{D I N}$ and to incorporate it into modeling approaches.

[25] The high temporal variation of $U_{D I N}$ as well as the lack of correlation between $U_{D I N}$ and environmental variables could be explained by the fact that each environmental factor (flow, temperature, nutrient concentration) may influence each particular DIN uptake and release process in a different way and to a different degree. In turn, such influence may vary over time depending on the structure and composition of stream microbial mats and the vegetative period of in-stream and near-stream primary producers. The balance between these interactive effects may modulate the magnitude of DIN uptake and release and, ultimately, the variation of $U_{D I N}$ over time. In concordance with this line of thought, we found a positive correlation between $U_{D I N}$ and temperature when considering only $U_{D I N}<0$. In addition, we found that only $U_{D I N}>0$ increased with stream DIN concentration. To explore whether the $U_{D I N}$ versus DIN concentration relationship hold across a larger range of values, we included in our analysis in-stream net DIN areal uptake rates from existing data reported in the literature. We found that this relationship was consistent across a wide range of stream DIN concentration (from $\sim 2$ to $800 \mu \mathrm{g} \mathrm{N}$ $\mathrm{L}^{-1}$ ) (Figure 5), and that there was not a linear but a log-log relationship between the two variables. The exponent of this $\log -\log$ relationship was $<1$, an indication that the 


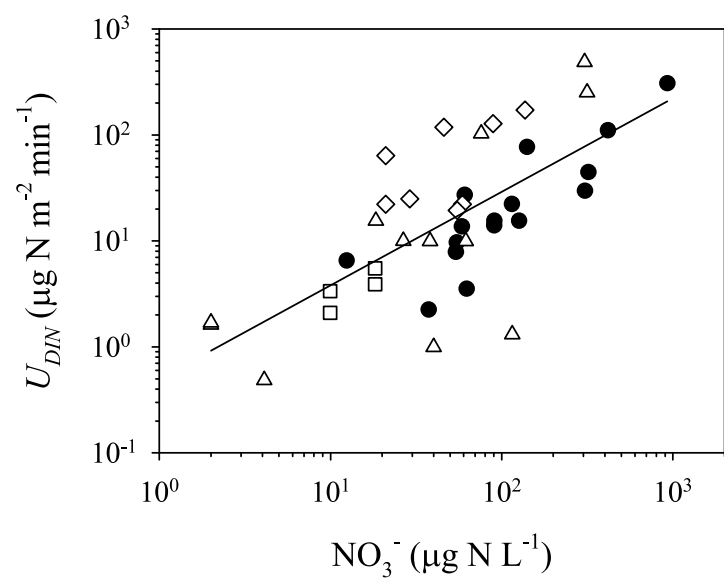

Figure 5. Log-log relationship $\left(y=0.499 x^{0.88}, \mathrm{r}^{2}=0.51\right.$, $\mathrm{p}<0.001, \mathrm{n}=40)$ between stream nitrate $\left(\mathrm{NO}_{3}^{-}\right)$concentration and in-stream net DIN areal uptake rate $\left(U_{D I N}\right)$ for the study catchments (black symbols; only $U_{D I N}>0$ values) and for other catchments reported in the literature (white symbols). Triangles for Bernhardt et al. [2002]; squares for Hubbard et al. [2010]; diamonds for Martí et al. [1997]. In-stream net areal uptake rate for nitrate was used when $U_{D I N}$ was not available.

efficiency of in-stream DIN net uptake decreases with increasing DIN availability (that is an efficiency loss effect sensu O'Brien et al. [2007]).

\subsection{The Potential Contribution of Stream Network DIN Retention to Catchment DIN Export}

[26] An important challenge in current stream biogeochemistry is transferring the knowledge acquired from reach-scale studies to the whole stream network [Ensign and Doyle, 2006]. In this study, we estimated the temporal variation of in-stream net DIN uptake at the reach scale, and incorporated it to two independent approaches to gain understanding on the implications that results found at the reach scale may have on regulating DIN export at the catchment scale. Both, empirical and model calculations converged to indicate that in-stream processes could substantially reduce annual catchment DIN export (from 4 to $38 \%$ ) under base flow conditions. This finding agrees with previous studies reporting that in-stream net DIN uptake can account for a significant decline in annual DIN export (920\%) [Mulholland et al., 2004; Williams et al., 2004].

[27] The two study catchments were subjected to different temperature and precipitation regimes, exhibited different stream water chemistry, and contrasting seasonality of DIN. In addition, only the semiarid catchment had a welldeveloped alluvial zone at the valley-bottom that could substantially affect in-stream DIN retention and release [Medici et al., 2010; Bernal and Sabater, 2012]. However, our empirical approach indicated that the contribution of annual stream network DIN retention to catchment DIN export varied more between years for a given catchment than between catchments within the same year. This result suggests that, at least under base flow conditions, inter-annual climatic variation was a more important driver of in-stream DIN cycling than differences in biogeochemical or physiographic characteristics between the study sites. Furthermore, the empirical approach indicated that consideration of temporal variation of $U_{D I N}$ significantly increased the potential contribution of the stream network to regulate catchment DIN export. This result evidences that single snapshot values do not cover the full range of in-stream responses, and thus, incorporating temporal variation in biogeochemical studies is important to understand the implications of stream functioning at greater temporal and spatial scales.

[28] Calculations based on the modeling approach showed larger differences in stream network DIN retention between streams than those observed with the empirical approach. Values of StrRet sim at the subhumid catchment were 10 times lower than at the semiarid catchment. A plausible explanation for this discrepancy between the two approaches could be that the modeled stream budgets of DIN had a strong dependency on the stream length parameter, which differed eightfold between the two study sites. In contrast, the empirical approach was based on the active area rather than on the length of the stream network, that on average only differed by fourfold between the semiarid and subhumid sites. This difference in length and area ratios between the two sites was due to the extreme contraction suffered by the semiarid stream during summer and fall that reduced dramatically the active area of the stream network (S. Bernal et al., Hydrological extremes modulate nutrient dynamics in Mediterranean climate streams across different spatial scales, submitted to Hydrobiologia, 2012). Since the stream length was a fix parameter in the INCA model, the modeling approach likely overestimated to some extent the annual contribution of stream network DIN retention to catchment DIN export, especially in the semiarid site. Moreover, model results showed low inter-annual variation of $S_{t r R e}$ sim $_{\text {sim }}$, which was likely due to both, the fact the stream length did not vary between years and the narrow temporal variation of the modeled in-stream uptake rates $\left(K_{c}^{T}, \mathrm{CV}<35 \%\right)$. Such limited temporal variation contrasted with that shown by the empirical estimates of $K_{c}(\mathrm{CV}>200 \%)$. This result suggests that stream water temperature, the variable that modulates $K_{c}$ within the INCA model, is not sufficient to account for the variation of $K_{c}$ observed in the studied streams.

[29] In this study, we investigated $U_{D I N}$ and its potential role on regulating catchment DIN export under base flow conditions. Noteworthy, in-stream DIN cycling can be limited during stormflow because high stream discharge reduces hydrological retention as well as the contact time between the water column and the streambed surface [Marti et al., 1997; Argerich et al., 2008]. If so, in-stream DIN uptake during stormflow could be low, thus diminishing the ability of in-stream processes to regulate catchment DIN export during stormflow conditions. Importantly, the contribution of stormflow to the total annual DIN export is not negligible: it can be high, and it can vary from year to year. For instance, in the studied semiarid catchment, DIN export during storm events can account for $52-88 \%$ of the annual DIN export depending on the annual precipitation regime [Bernal et al., 2002]. Likewise, DIN export during snowmelt can account for more than half of the total annual DIN export in temperate catchments [Likens and Bormann, 1995]. Therefore, the implications of our results to annual catchment budgets need to be considered within the context of the relative contribution of base flow to the annual stream DIN flux, which will depend on the annual precipitation 
regime and, ultimately, on climatic variation. Further empirical studies including measurements of in-stream DIN cycling under different hydrological conditions could establish upon which value of stream discharge in-stream DIN processes effectively operate, thus elucidating to a better extent the potential of in-stream cycling on regulating catchment DIN exports [Doyle, 2005].

\section{Conclusions}

[30] This study contributes to fill the current gap of knowledge on in-stream net DIN uptake by showing that headwater streams are biogeochemically dynamic systems that can alternatively act as net DIN sinks $\left(U_{D I N}>0\right)$, net DIN sources $\left(U_{D I N}<0\right)$, or be at steady state $\left(U_{D I N} \sim 0\right)$. In addition, we showed with two independent approaches that in-stream net DIN uptake during periods of biogeochemical disequilibrium $\left(U_{D I N} \neq 0\right)$ could influence annual stream network DIN retention, and thus regulate annual catchment DIN export under base flow conditions. Although both approaches applied in this study pointed toward the same direction, we found some discrepancies between our empirical and model calculations, in part resulting from the low capacity of the modeled in-stream DIN uptake to cope with its natural variation. Modeling tools can help understanding linkages between terrestrial and aquatic ecosystems as well as predicting changes in water and nutrient export under global change scenarios. Our results suggest that instream net DIN uptake results from complex interactions among several factors, which difficult the prediction of its temporal variation. Further work is needed to understand the key factors controlling net DIN uptake in stream ecosystems and to successfully incorporate in-stream DIN cycling and its temporal variation into modeling approaches at both, reach- and watershed-scales.

[31] Acknowledgments. The authors thank M. Ribot, A. Argerich, P. Fonollà, and S. Pla for field and laboratory assistance, and A. Oltra for helping with GIS. S.B.'s research was funded with a Juan de la Cierva postdoctoral contract (JCI-2008-1777) from the Spanish Ministry of Science and Innovation (MICINN) and a JAEDOC contract (JAEDOC027) from the Spanish Research Council. D.vS.'s research was supported by a fellowship of the German Academic Exchange Service/"laCaixa" Foundation and a Juan de la Cierva postdoctoral contract (JCI-2010-06397) from the MICINN. Financial support was provided by the MICINN (MONTESConsolider, CSD-2008-00040) and the EU-funded projects EURO-LIMPACS (GOCE-CT-2003-505540) and REFRESH (FP7-ENV-2009-1-244121).

\section{References}

Acuña, V., A. Giorgi, I. Muñoz, U. Uehlinger, and S. Sabater (2004), Flow extremes and benthic organic matter shape the metabolism of a headwater Mediterranean stream, Freshwater Biol., 49, 960-971, doi:10.1111/ j.1365-2427.2004.01239.x.

Argerich, A., E. Martí, F. Sabater, M. Ribot, D. von Schiller, and J. L. Riera (2008), Combined effects of leaf litter inputs and a flood on nutrient retention in a Mediterranean mountain stream during fall, Limnol. Oceanogr., 53(2), 631-641, doi:10.4319/lo.2008.53.2.0631.

Bernal, S., and F. Sabater (2012), Changes in discharge and solute dynamics between hillslope and valley-bottom intermittent streams, Hydrol. Earth Syst. Sci., 16, 1595-1605, doi:10.5194/hess-16-1595-2012.

Bernal, S., A. Butturini, and F. Sabater (2002), Variability of DOC and nitrate responses to storms in a small Mediterranean forested catchments, Hydrol. Earth Syst. Sci., 6, 1031-1041, doi:10.5194/hess-6-1031-2002.

Bernal, S., A. Butturini, and F. Sabater (2005), Seasonal variations of dissolved nitrogen and DOC:DON ratios in an intermittent Mediterranean stream, Biogeochemistry, 75, 351-372, doi:10.1007/s10533-005-1246-7.

Bernhardt, E. S., R. O. Hall Jr., and G. E. Likens (2002), Whole-system estimates of nitrification and nitrate uptake in streams of the Hubbard Brook
Experimental Forest, Ecosystems (N. Y.), 5, 419-430, doi:10.1007/ s10021-002-0179-4.

Bernhardt, E. S., G. E. Likens, D. C. Buso, and C. T. Driscoll (2003), In-stream uptake dampens effects of major forest disturbance on watershed nitrogen export, Proc. Natl. Acad. Sci. U. S. A., 100(18), 10,304-10,308, doi:10.1073/pnas. 1233676100

Bormann, F. H., and G. E. Likens (1967), Nutrient cycling, Science, 155(3761), 424-429, doi:10.1126/science.155.3761.424.

Boyer, E. W., R. B. Alexander, W. J. Parton, C. S. Li, K. Butterbach-Bahl, S. D. Donner, R. W. Skaggs, and S. J. Del Gross (2006), Modeling denitrification in terrestrial and aquatic ecosystems at regional scales, Ecol. Appl., 16(6), 2123-2142, doi:10.1890/1051-0761(2006)016[2123: MDITAA]2.0.CO;2.

Brookshire, E. N., H. M. Valett, and S. Gerber (2009), Maintenance of terrestrial nutrient loss signatures during in-stream transport, Ecology, 90(2), 293-299, doi:10.1890/08-0949.1.

Butturini, A., and F. Sabater (1998), Ammonium and phosphate retention in a Mediterranean steram: Hydrological versus temperature control, Can. J. Fish. Aquat. Sci., 55, 1938-1945, doi:10.1139/f98-071.

Campbell, C. P., and J. M. Norman (1998), An Introduction to Environmental Biophysics, 2nd ed., 281 pp., Springer, New York.

Doyle, M. W. (2005), Incorporating hydrologic variability into nutrient spiraling, J. Geophys. Res., 110, G01003, doi:10.1029/2005JG000015. Ensign, S. H., and M. W. Doyle (2006), Nutrient spiraling in streams and river networks, J. Geophys. Res., 111, G04009, doi:10.1029/ 2005JG000114.

Gordon, N. D., T. A. McMahon, B. L. Finlayson, C. J. Gippel, and R. J. Nathan (2004), Stream Hydrology: An Introduction for Ecologists, 2nd ed., John Wiley, Chichester, U. K.

Grimm, N. B., S. G. Fisher, and W. L. Minckley (1981), Nitrogen and phosphorus dynamics in hot desert streams of Southwestern U.S.A., Hydrobiologia, 83(2), 303-312, doi:10.1007/BF00008281.

Hall, R. O., M. A. Baker, C. D. Arp, and B. J. Koch (2009a), Hydrological control of nitrogen removal, storage, and export in a mountain stream, Limnol. Oceanogr., 54(6), 2128-2142, doi:10.4319/lo.2009.54.6.2128.

Hall, R. O., et al. (2009b), Nitrate removal in stream ecosystems by ${ }^{15} \mathrm{~N}$ addition experiments: Total uptake, Limnol. Oceanogr., 54(3), 653-665, doi:10.4319/lo.2009.54.3.0653.

Helton, A. M., et al. (2011), Thinking outside the channel: Modeling nitrogen cycling in networked river ecosystems, Front. Ecol. Environ, 9(4), 229-238, doi:10.1890/080211.

Hubbard, K. A., L. K. Lautz, M. J. Mitchell, B. Mayer, and E. R. Hotchkiss (2010), Evaluating nitrate uptake in a Rocky Mountains stream using labelled ${ }^{15} \mathrm{~N}$ and ambient nitrate chemistry, Hydrol. Processes, 24(23), 3322-3336, doi:10.1002/hyp.7764.

Likens, G. E., and F. H. Bormann (1995), Biogeochemistry of a Forested Ecosystem, 2nd ed., Springer, Berlin, doi:10.1007/978-1-4612-4232-1.

Martí, E., N. B. Grimm, and S. G. Fisher (1997), Pre- and post-flood retention efficiency of nitrogen in a Sonoran Desert stream, J. N. Am. Benthol. Soc., 16, 805-819, doi:10.2307/1468173

Medici, C., S. Bernal, A. Butturini, F. Sabater, M. Martin, A. J. Wade, and F. Frances (2010), Modelling the inorganic nitrogen behaviour in a small Mediterranean forested catchment, Fuirosos (Catalonia), Hydrol. Earth Syst. Sci., 14, 223-237, doi:10.5194/hess-14-223-2010.

Mulholland, P. J., and J. R. Webster (2010), Nutrient dynamics in streams and the role of J-NABS, J. N. Am. Benthol. Soc., 29(1), 100-117, doi:10.1899/08-035.1.

Mulholland, P. J., H. M. Valett, J. R. Webster, S. A. Thomas, L. W. Copper, S. K. Hamilton, and B. J. Peterson (2004), Stream denitrification and total nitrate uptake rates measured using a field ${ }^{15} \mathrm{~N}$ tracer addition approach, Limnol. Oceanogr., 49(3), 809-820, doi:10.4319/lo.2004.49.3.0809.

Mulholland, P. J., et al. (2008), Stream denitrification across biomes and its response to anthropogenic nitrate loading, Nature, 452(7184), 202-205, doi:10.1038/nature06686

Newbold, J. D. (1996), Cycles and spirals of nutrients, in River Flows and Channel Forms, edited by G. Petts and P. Calow, pp. 130-159, Blackwell Sci., Oxford, U. K.

Ninyerola, M., X. Pons, and J. M. Roure (2000), A methodological approach of climatological modelling of air temperature and precipitation through GIS techniques, Int. J. Climatol., 20, 1823-1841, doi:10.1002/ 1097-0088(20001130)20:14<1823::AID-JOC566>3.0.CO;2-B

O'Brien, J. M., W. K. Dodds, K. C. Wilson, J. N. Nurdock, and J. Eichmiller (2007), The saturation of $\mathrm{N}$ cycling in Central Plains streams: ${ }^{15} \mathrm{~N}$ experiments across a broad gradient of nitrate concentrations, Biogeochemistry, 84, 31-49, doi:10.1007/s10533-007-9073-7.

Peterson, B. J., et al. (2001), Controls of nitrogen export from watersheds by headwater streams, Science, 292, 86-90, doi:10.1126/science. 1056874 . 
Roberts, B. J., and P. J. Mulholland (2007), In-stream biotic control of nutrient biogeochemistry in a forested stream, West Fork of Walker Branch, J. Geophys. Res., 112, G04002, doi:10.1029/2007JG000422.

von Schiller, D., E. Martí, J. L. Riera, M. Ribot, A. Argerich, P. Fonollà, and F. Sabater (2008), Inter-annual, annual, and seasonal variation of $\mathrm{P}$ and $\mathrm{N}$ retention in a perennial and an intermittent stream, Ecosystems (N. Y.), 11, 670-687, doi:10.1007/s10021-008-9150-3.

von Schiller, D., S. Bernal, and E. Martí (2011), Technical note: A comparison of two empirical approaches to estimate in-stream net nutrient uptake, Biogeosciences, 8, 875-882, doi:10.5194/bg-8-875-2011.

Wade, A. J., P. Durand, V. Beaujouan, W. W. Wessel, K. J. Raat, P. G. Whitehead, D. Butterfield, K. Rankinen, and A. Lepisto (2002), A nitrogen model for European catchments: INCA, new model structure and equations, Hydrol. Earth Syst. Sci., 6(3), 559-582, doi:10.5194/ hess-6-559-2002.

Wade, A. J., D. Butterfield, and P. G. Whitehead (2006), Towards an improved understanding of the nitrate dynamics in lowland, permeable river-systems: Applications of INCA-N, J. Hydrol., 330, 185-203, doi:10.1016/j.jhydrol.2006.04.023.

Williams, M., C. Hopkinson, E. Rastetter, and J. Vallino (2004), N budgets and aquatic uptake in the Ipswich River basin, northeastern Massachusetts, Water Resour. Res., 40, W11201, doi:10.1029/2004WR003172.

Wollheim, W. M., C. J. Vorosmarty, B. J. Peterson, S. P. Seitzinger, and C. S. Hopkinson (2006), Relationship between river size and nutrient removal, Geophys. Res. Lett., 33, L06410, doi:10.1029/2006GL025845.

Zar, J. H. (2010), Biostatistical Analysis, 5th ed., Prentice Hall, Upper Saddle River, N. J. 